OPEN ACCESS

Edited by:

Qi Yuan,

Memorial University, Canada

Reviewed by:

Thomas Launey,

RIKEN, Japan

Christian Hansel,

University of Chicago, USA

*Correspondence:

Chun-Ping Chu

cpchu@ybu.edu.cn

De-Lai Qiu

dlqiu@ybu.edu.cn

tThese authors have contributed equally to this work.

Received: 31 May 2016 Accepted: 16 June 2016

Published: 30 June 2016

Citation:

Liu H, Lan Y, Bing Y-H, Chu C-P and Qiu D-L (2016)

N-methyl-D-Aspartate Receptors

Contribute to Complex Spike Signaling in Cerebellar Purkinje Cells:

An In vivo Study in Mice.

Front. Cell. Neurosci. 10:172.

doi: 10.3389/fncel.2016.00172

\section{N-methyl-D-Aspartate Receptors Contribute to Complex Spike Signaling in Cerebellar Purkinje Cells: An In vivo Study in Mice}

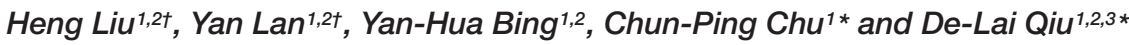 \\ ${ }^{1}$ Cellular Function Research Center, Yanbian University, Yanji, China, ${ }^{2}$ Department of Physiology and Pathophysiology, \\ College of Medicine, Yanbian University, Yanji, China, ${ }^{3}$ Key Laboratory of Natural Resource of the Changbai Mountain and \\ Functional Molecular of the Ministry of Education, Yanbian University, Yanji, China
}

$N$-methyl-D-aspartate receptors (NMDARs) are post-synaptically expressed at climbing fiber-Purkinje cell (CF-PC) synapses in cerebellar cortex in adult mice and contributed to CF-PC synaptic transmission under in vitro conditions. In this study, we investigated the role of NMDARs at CF-PC synapses during the spontaneous complex spike (CS) activity in cerebellar cortex in urethane-anesthetized mice, by in vivo whole-cell recording technique and pharmacological methods. Under current-clamp conditions, cerebellar surface application of NMDA (50 $\mu \mathrm{M})$ induced an increase in the CS-evoked pause of simple spike (SS) firing accompanied with a decrease in the SS firing rate. Under voltageclamp conditions, application of NMDA enhanced the waveform of CS-evoked inward currents, which expressed increases in the area under curve (AUC) and spikelet number of spontaneous CS. NMDA increased the AUC of spontaneous CS in a concentrationdependent manner. The $\mathrm{EC}_{50}$ of NMDA for increasing AUC of spontaneous CS was $33.4 \mu \mathrm{M}$. Moreover, NMDA significantly increased the amplitude, half-width and decay time of CS-evoked after-hyperpolarization (AHP) currents. Blockade of NMDARs with D-(-)-2-amino-5-phosphonopentanoic acid (D-APV, $250 \mu \mathrm{M})$ decreased the AUC, spikelet number, and amplitude of AHP currents. In addition, the NMDA-induced enhancement of CS activity could not be observed after $\alpha$-amino-3-hydroxy-5-methyl-4isoxazolepropionic acid receptors were blocked. The results indicated that NMDARs of CF-PC synapses contributed to the spontaneous CS activity by enhancing CS-evoked inward currents and AHP currents.

Keywords: $\boldsymbol{N}$-methyl-D-aspartate (NMDA), cerebellar purkinje cell, in vivo whole-cell patch-clamp recording, complex spike (CS), after-hyperpolarization (AHP)

\section{INTRODUCTION}

$\mathrm{N}$-Methyl-D-aspartate receptors (NMDARs) are widely expressed in the central nervous system, which play important roles in synaptic transmission and synaptic plasticity in adult cerebellar cortex (Dingledine et al., 1999; Cull-Candy et al., 2001). There are three main subunits of NMDA receptor have been identified, NMDAR, $\mathrm{NMDAR}_{2}$, and $\mathrm{NMDAR}_{3}$ (Cull-Candy et al., 2001; Neyton and Paoletti, 2006). Earlier studies have illustrated that cerebellar Purkinje cells (PCs) in immature rodents express $\mathrm{NMDAR}_{1}$ and $\mathrm{NMDAR}_{2}$ (Dupont et al., 1987; Rosenmund et al., 1992; Cull-Candy et al., 1998), and electrophysiological recordings have concluded 
that functional NMDA receptors no longer express after the first postnatal week (Konnerth et al., 1990; Llano et al., 1991; Farrant et al., 1994). however, $\mathrm{NMDAR}_{1}$ and $\mathrm{NMDAR}_{2}$ subunits have been later found in PCs of adult mice (Nakagawa et al., 1996; Hafidi and Hillman, 1997; Thomson, 2000), and NMDA evokes responses have been recorded in cerebellar PCs of the adult rat and mouse under in vitro conditions (Dupont et al., 1987; Billard and Pumain, 1989). Moreover, we recently found that cerebellar surface application of NMDA failed to excite PCs but increased spike firing of molecular layer interneurons (MLIs), resulting in an inhibition in spontaneous SS firing rate of PCs in vivo in mice (Liu et al., 2014).

Cerebellar cortical PCs receive information via the mossy fiber-parallel fiber (MF-PF) and the climbing fiber (CF) pathways. Activation of the CF evokes a powerful and infrequent allor none complex spikes (CSs), consisting of a brief burst of ordinary action potentials and $\mathrm{Ca}^{2+}$-dependent dendritic spikes (Eccles et al., 1966), which plays a central role in behaviors by generating excitatory post-synaptic potentials (EPSPs) to PCs (Simpson et al., 1996). CS is thought to represent a critical signal for the operation of the cerebellar cortex, conveying both timing information (Welsh and Llinás, 1996) and triggering synaptic plasticity (Gilbert and Thach, 1977; Hansel et al., 2001; Ito, 2001). Under in vivo conditions, CF discharge can control the frequency and pattern of PC spike output by punctuating tonic activity with a variable duration pauses, slow the frequency of simple spike (SS) discharge (Ebner and Bloedel, 1981; Ebner et al., 1983; Barmack and Yakhnitsa, 2003; Cerminara and Rawson, 2004).

$N$-methyl-D-aspartate receptors have been suggested that contributed less to CF activation-mediate inward currents (Otis et al., 1997; Auger and Attwell, 2000). However, NMDARs were post-synaptically expressed at CF-PC synapses and contributed to the waveform of the CF stimulation-induced CS in cerebellar slices of adult mice (Piochon et al., 2007). The NMDARsmediated CF-PC synaptic transmission develops with maturation of PCs, which is hardly detectable before postnatal day 21, and reach full expression levels at 8 weeks after birth (Piochon et al., 2007; Renzi et al., 2007). Using NMDAR2D-/-mice, it has been found NMDARs-mediated excitatory post-synaptic currents (EPSCs) could be evoked by CF stimulation via activation of NMDAR2A subunit (Renzi et al., 2007). In addition, the functional NMDARs in PCs of 2-3-months-old rats have also been demonstrated in contribution of CF-evoked EPSCs (Bidoret et al., 2009).

Collectively, NMDARs are post-synaptically expressed at CFPC synapses and contributed to the waveform of the CF stimulation-induced CS under in vitro conditions. However, the role of CF-PC NMDARs in intact cerebellar cortex of living mouse is currently unclear.

\section{MATERIALS AND METHODS}

\section{Anesthesia and Surgical Procedures}

The anesthesia and surgical procedures have been described previously (Chu et al., 2011a,b). In brief, the experimental procedures were approved by the Animal Care and Use
Committee of Jilin University and were in accordance with the animal welfare guidelines of the U.S. National Institutes of Health. The permit number is SYXK (Ji) 2007-0011. Thirty nine adult (6-8-weeks-old) HA/ICR mice were anesthetized with urethane (1.3 g/kg body weight i.p.), and each mouse only recorded one $\mathrm{PC}$ in this study (six mice failed to obtain wholecell recordings of PCs). A watertight chamber was created and a 1-1.5 mm craniotomy was drilled to expose the cerebellar surface corresponding to Vermis VI-VII. The brain surface was constantly superfused with oxygenated artificial cerebrospinal fluid (ACSF: $125 \mathrm{mM} \mathrm{NaCl}, 3 \mathrm{mM} \mathrm{KCl}, 1 \mathrm{mM} \mathrm{MgSO}_{4}$, $2 \mathrm{mM} \mathrm{CaCl}_{2}, 1 \mathrm{mM} \mathrm{NaH} \mathrm{PO}_{4}, 25 \mathrm{mM} \mathrm{NaHCO}_{3}$, and $10 \mathrm{mM}$ D-glucose) with a peristaltic pump (Gilson Minipulse 3; Villiers, Le Bel, France) at $0.4 \mathrm{ml} / \mathrm{min}$. Rectal temperature was monitored and maintained at $37.0 \pm 0.2^{\circ} \mathrm{C}$ using body temperature equipment.

\section{Electrophysiological Recording and Drug Application}

In vivo cell-attached and whole-cell patch-clamp recordings from PCs were performed with an Axopatch-200B amplifier (Molecular Devices, Foster City, CA, USA). The signals of PC whole-cell recordings were acquired through a Digidata 1440 series analog-to-digital interface on a personal computer using Clampex 10.3 software. Patch pipettes were made with a puller (PB-10; Narishige, Tokyo, Japan) from thick-wall borosilicate glass (GD-1.5; Narishige). Patch electrodes (4$6 \mathrm{M} \Omega$ ) contained a solution of the following composition (in $\mathrm{mM}$ ): potassium gluconate 120 , HEPES 10, EGTA $1, \mathrm{KCl}$ 5, $\mathrm{MgCl}_{2}$ 3.5, $\mathrm{NaCl} 4$, biocytin 8, $\mathrm{Na}_{2}$ ATP 4, and $\mathrm{Na}_{2}$ GTP 0.2 ( $\mathrm{pH} 7.3$ with $\mathrm{KOH}$, osmolarity adjusted to $300 \mathrm{mOsm}$ ). The whole-cell recordings from PCs were performed at depths 150-200 $\mu \mathrm{m}$ under pia mater membrane, and identified by regular spontaneous SS accompanied with irregular CS, and confirmed by biocytinhistochemistry (Chu et al., 2011a). The series resistances were in a range of 10-40 $\mathrm{M} \Omega$, compensated by $80 \%$. Membrane voltage and current were filtered at $2 \mathrm{kHz}$, digitized at $20 \mathrm{kHz}$. The reagents included $N$-methyl-D-aspartate (NMDA), D-(-)-2-amino-5-phosphonopentanoic acid (D-APV), SR95531, hydrobromide (6-imino-3-(4-methoxyphenyl)-1(6H)pyridazinebutanoic acid hydrobromide) and NBQX (2,3-dioxo6-nitro-1,2,3,4-tetrahydrobenzo[f] quinoxaline-7- sulfonamide) were purchased from Sigma-Aldrich (Shanghai, China). The drugs were dissolved in ACSF, and applied directly onto the cerebellar surface for $5 \mathrm{~min}$ by a peristaltic pump $(0.5 \mathrm{ml} / \mathrm{min})$.

\section{Histochemistry}

After the experiments, the whole brain was removed and fixed in $4 \%$ paraformaldehyde in 0.1 PBS ( $\mathrm{pH} 7.4$ ) at $4^{\circ} \mathrm{C}$ for $24 \mathrm{~h}$. Slices were cut in the sagittal plane at $200 \mu \mathrm{m}$ using a vibratome (NVSLM1, Campden Instruments LTD, Loughborough, England), and washed with PBS. The tissue was reacted overnight with an avidin-biotin complex (ABC Elite kit; Vector Laboratories, Burlingame, CA, USA) at $4^{\circ} \mathrm{C}$. Finally, biocytin binding was visualized by $3,3^{\prime}$-diaminobenzidine tetrahydrochloride histochemistry. 


\section{Data Analysis}

The electrophysiological data were analyzed using Clampfit 10.3 software. Spontaneous activities of SS and CS were calculated from a train of interspike intervals recorded for $100 \mathrm{~s}$ of baseline, in the presence of drugs and washout $(20 \mathrm{~min})$. All the data were normalized with baseline and used for analyses. Values are expressed as the mean \pm SEM. Student's paired $t$-test and one-way ANOVA (SPSS software; Chicago, IL, USA) were used to determine the level of statistical significance between groups of data. $P$-values below 0.05 were considered to indicate a statistically significant difference between experimental groups.

\section{RESULTS}

\section{Effects of NMDA on CS Activity of the Cerebellar PCs}

Under cell-attached recording conditions, PCs were identified by regular SS firing and the presence of irregular CS (Ito, 1984; Chu et al., 2011b). These PCs exhibited irregular CS firing at mean rates of $0.9 \pm 0.3 \mathrm{~Hz}(n=8)$ recorded in cerebellar cortex Vermis VII. The highest and lowest rates of CS firing were 1.9 and $0.1 \mathrm{~Hz}$, respectively. Consistent with our previous study (Liu et al., 2014), cerebellar surface perfusion of $50 \mu \mathrm{M}$ NMDA for $5 \mathrm{~min}$ induced depression in the frequency of SS firing rate of PCs (Figure 1A), the normalized SS firing rate was $44.2 \pm 4.8 \%$ of baseline $(100.0 \pm 3.2 \% ; n=8 ; P<0.001$; Figure 1B). However, NMDA induced a significant increase in pause of SS firing (Figures 1A,C), the normalized pause of SS firing was $253.4 \pm 9.5 \%$ of baseline $(100.0 \pm 3.2 \%$; $n=8$; $P<0.001$; Figure 1C). The effect of NMDA on SS firing rate of PCs was recovered after washout for $20 \mathrm{~min}$. These results suggested that extracellular application of NMDA modulated CS activity of the PCs.

For understand the effect of NMDA on CS-evoked membrane currents of PCs, we further performed in vivo whole-cell patchclamp recording in a total 25 cerebellar PCs. Under voltage-clamp recording conditions $\left(\mathrm{V}_{\text {hold }}=-70 \mathrm{mV}\right)$, the spontaneous CS expressed strong inward currents with high frequency spiklets, followed by outward currents (Figures $2 \mathbf{A}, \mathbf{F}$ ). The mean value of outward currents was $107.4 \pm 4.7 \mathrm{pA}$ ( $n=25$; not shown). The number of spikelets was $2-5$ and the mean frequency of them was $406 \pm 6.5 \mathrm{~Hz}(n=25$; not shown). Cerebellar surface perfusion of NMDA $(50 \mu \mathrm{M})$ did not significantly change the frequency (Figures 2A,B) and peak amplitude (Figures 2A,C) of spontaneous CS, but increased the area under curve (AUC) of CS-evoked inward currents by $151.6 \pm 6.9 \%$ of baseline (ACSF: $100.0 \pm 5.5 \% ; n=8 ; P<0.05$; Figures 2A,D). NMDA also significantly increased number of spikelets to $115.6 \pm 5.2 \%$ of baseline (ACSF: $100.0 \pm 3.9 \% ; n=8 ; P<0.05$; Figures 2A,E). NMDA increased the AUC of CS in a concentration-dependent manner (Figure 3). AUC of CS was significantly increased by $8.9 \pm 5.1 \%$ of control (ACSF) with $5 \mu \mathrm{M}$ NMDA $(n=6$; Figure 3), and the $50 \%$ effective concentration $\left(\mathrm{EC}_{50}\right)$ was $33.4 \mu \mathrm{M}$. AUC of CS was significantly $(P<0.001)$ increased by $64.1 \pm 6.7 \%$ of baseline with $200 \mu \mathrm{M}$ NMDA $(n=5$;
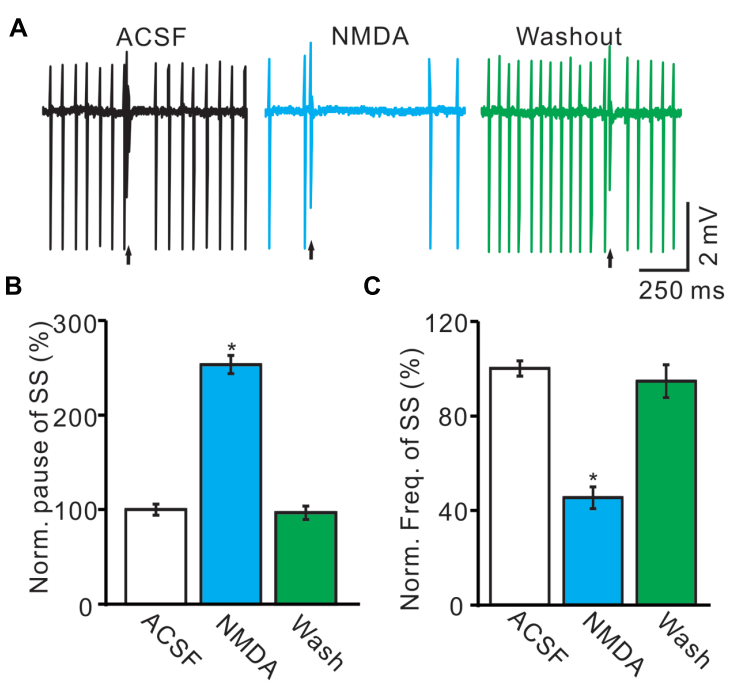

FIGURE 1 | Effects of NMDA on the spontaneous SS and CS of cerebellar PCs. (A) Representative traces showing that the spontaneous activity from of a PC in treatments: ACSF, NMDA (50 $\mu \mathrm{M})$ with overlapped trace of ACSF, and washout. Arrows indicated CS. (B) Summary of data showing the normalized SS firing rate of each treatment. (C) Bar graph showing the normalized pause of SS in ACSF, NMDA and washout. $* P<0.05 ; n=8$.

Figure 3). Consistent with previous studies (Piochon et al., 2007, 2010; Renzi et al., 2007), our results indicated that extracellular application of NMDA dose-dependently enhanced the strength of CS activity in vivo in mice.

\section{NMDA Enhanced CS-Evoked After-Hyperpolarzation (AHP) Currents}

The CS evoked outward currents have been identified as AHP currents, which have been assumed to be critical for regulation of the frequency and pattern of PC SS output (McKay et al., 2007), we therefore examined that effect of NMDA on properties of AHP currents. As shown in Figure 4, application of NMDA significantly affected the waveforms of the spontaneous CS firing. In the presence of NMDA $(50 \mu \mathrm{M})$, the normalized amplitude of AHP currents was increased to $126.9 \pm 5.9 \%$ of baseline (ACSF: $100.0 \pm 5.1 \% ; n=8 ; P<0.05$; Figures 4A,B). The normalized half-width of AHP currents was increased to $116.4 \pm 6.1 \%$ of baseline (ACSF: $100.0 \pm 4.4 \% ; n=8 ; P<0.05$; Figures 4A,C). In addition, NMDA significantly decreased the rise time of AHP currents to $86.3 \pm 6.1 \%$ of baseline (ACSF: $100.0 \pm 4.8 \% ; n=8$; $P<0.05$; Figures 4A,D). However, the normalized decay time of AHP currents was significantly increased to $122.1 \pm 6.3 \%$ of baseline (ACSF: $100.0 \pm 5.6 \% ; n=8 ; P<0.05$; Figures 4A,E). These results indicated that NMDA enhanced the amplitude and the dynamic properties of AHP currents in vivo in mice.

\section{Blockade of NMDA Receptor Attenuated the Activity of Spontaneous CS}

We further used an NMDA antagonist, D-APV $(250 \mu \mathrm{M})$ to determine whether the functional NMDARs were activated 


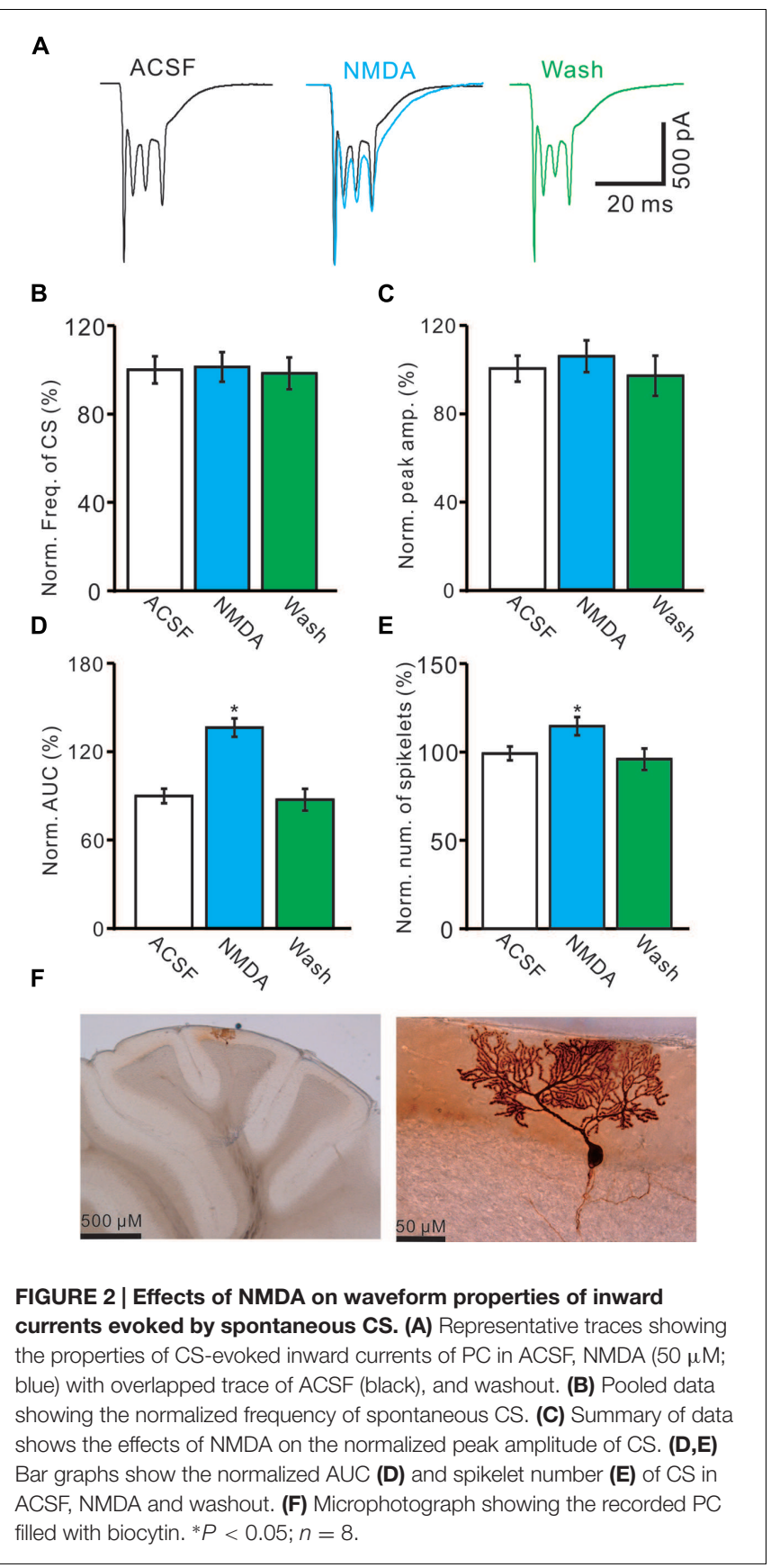

during the spontaneous CS spike firing in living mouse. In the presence of D-APV, the normalized pause of SS firing was decreased to $82.1 \pm 5.1 \%$ of baseline $(100.0 \pm 4.7 \% ; n=6$; $P<0.001$; Figure 5B), and the normalized number of spikelets was decreased to $86.4 \pm 6.3 \%$ of baseline (ACSF: $100.0 \pm 4.6 \%$; $n=6 ; P<0.05$; Figures 5A,C). Moreover, D-APV induced a significant decrease in the AUC of CS-evoked excitatory potentials to $74.6 \pm 7.1 \%$ of baseline (ACSF: $100.0 \pm 4.6 \%$; $n=6 ; P<0.05$; Figures 5A,D), and the normalized amplitude of AHP potential was decreased to $85.1 \pm 6.7 \%$ of baseline (ACSF: $100.0 \pm 5.8 \% ; n=6 ; P<0.05$; Figures $5 \mathrm{~A}, \mathbf{E})$. These results

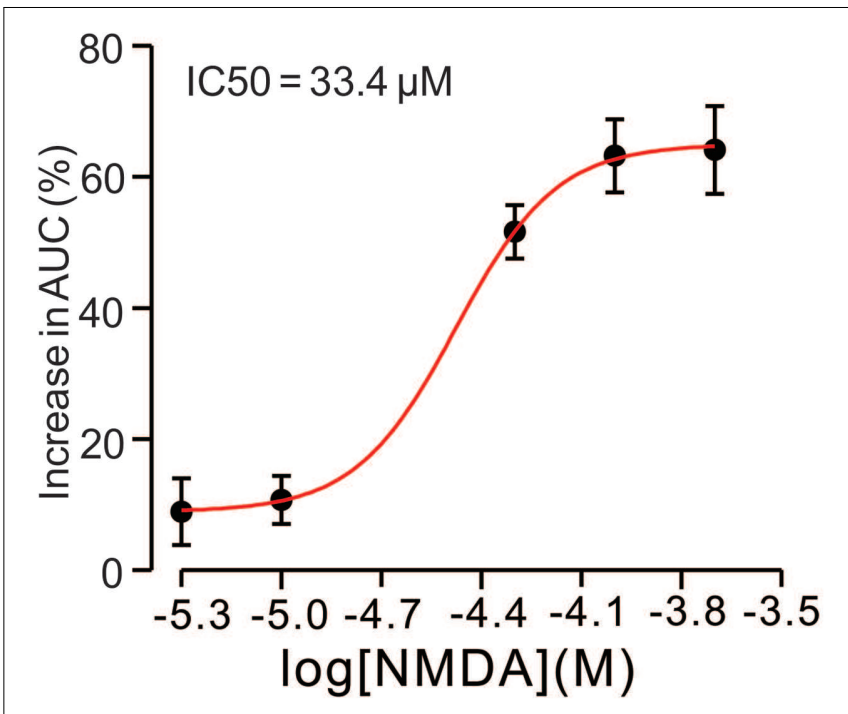

FIGURE 3 | $\mathbf{N}$-methyl-D-aspartate receptor (NMDA)-induced increase in AUC of CS is in a dose-dependent manner. Bath application of NMDA enhanced the AUC of CS in a dose-dependent manner $\left(\mathrm{I}_{50}=33.4 \mu \mathrm{M}\right)$. The number of the recorded PCs tested for each concentration is indicated near the bars.

indicated that blockade of CF-PC synaptic NMDA receptor attenuated the strength of spontaneous CS activity in living mice.

\section{Blockade AMPA Receptors Abolished Spontaneous CS Firing and NMDARs Activity}

For understanding the functional relationships between NMDARs and $\alpha$-amino-3-hydroxy-5-methyl-4-isoxazolepropionic acid receptors (AMPARs) during the spontaneous CS activity, we employed AMPARs antagonist, NBQX. In these experiments, we also used $\mathrm{GABA}_{\mathrm{A}}$ receptor antagonist, gabazine (SR95531, $20 \mu \mathrm{M})$ to prevent inhibitory effects of MLIs. In the presence of gabazine, NBQX $(50 \mu \mathrm{M})$ completely blocked the spontaneous CS activity (Figure 6A). The normalized frequency of CS $(0 \pm 0 \%)$ was significant lower that in control conditions (ACSF: $100.0 \pm 7.1 \% ; n=6 ; P<0.05$ vs. control; Figures $6 \mathbf{6 A , B}$ ). Additional application of NMDA could not restored the CS activity (Figures 6A,B). These results indicated that the spontaneous activity of CS was mediated predominantly by AMPARs, but activation of NMDARs might enhance the spontaneous CS firing activity of PCs.

The frequency of SS firing was unaffected by blocking of $\mathrm{GABA}_{\mathrm{A}}$ receptors activity, but blockade CS activity with NBQX induced an increase in SS firing rate to $132.4 \pm 4.6 \%$ of control $(100 \pm 4.2 \% ; n=6 ; P<0.05$ vs. control; Figures 6A,C). Additional application of NMDA induced a further increase in SS firing rate to $145.3 \pm 6.2 \%$ of control $(100 \pm 4.2 \% ; n=6 ; P<0.05$ vs. control; Figures $6 \mathrm{~A}, \mathbf{C})$. These results indicated that blockade CS activity increased SS firing rate of PCs in cerebellar folium Vermis I-II, 


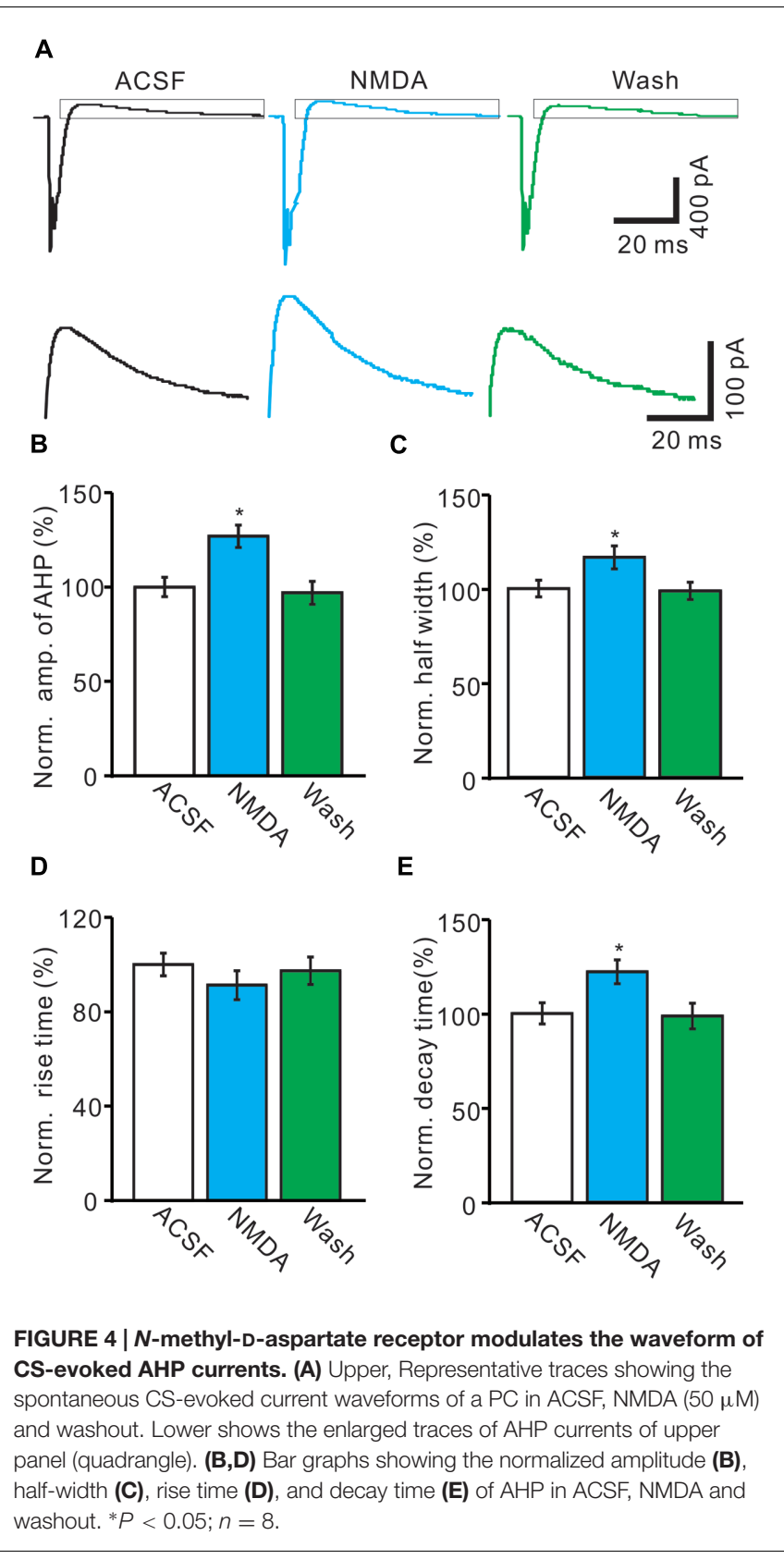

suggesting that CS activity modulated SS spike activity in vivo in mice (Ebner and Bloedel, 1981; Ebner et al., 1983; Barmack and Yakhnitsa, 2003; Cerminara and Rawson, 2004).

\section{DISCUSSION}

In the present study, we mainly found that extracellular application of NMDA dose-dependently enhanced the strength of spontaneous CS activity, whereas NMDA blocker attenuated the strength of CS activity in vivo in mice. Our results indicated that NMDA receptors of CF-PC synapses contributed to spontaneous

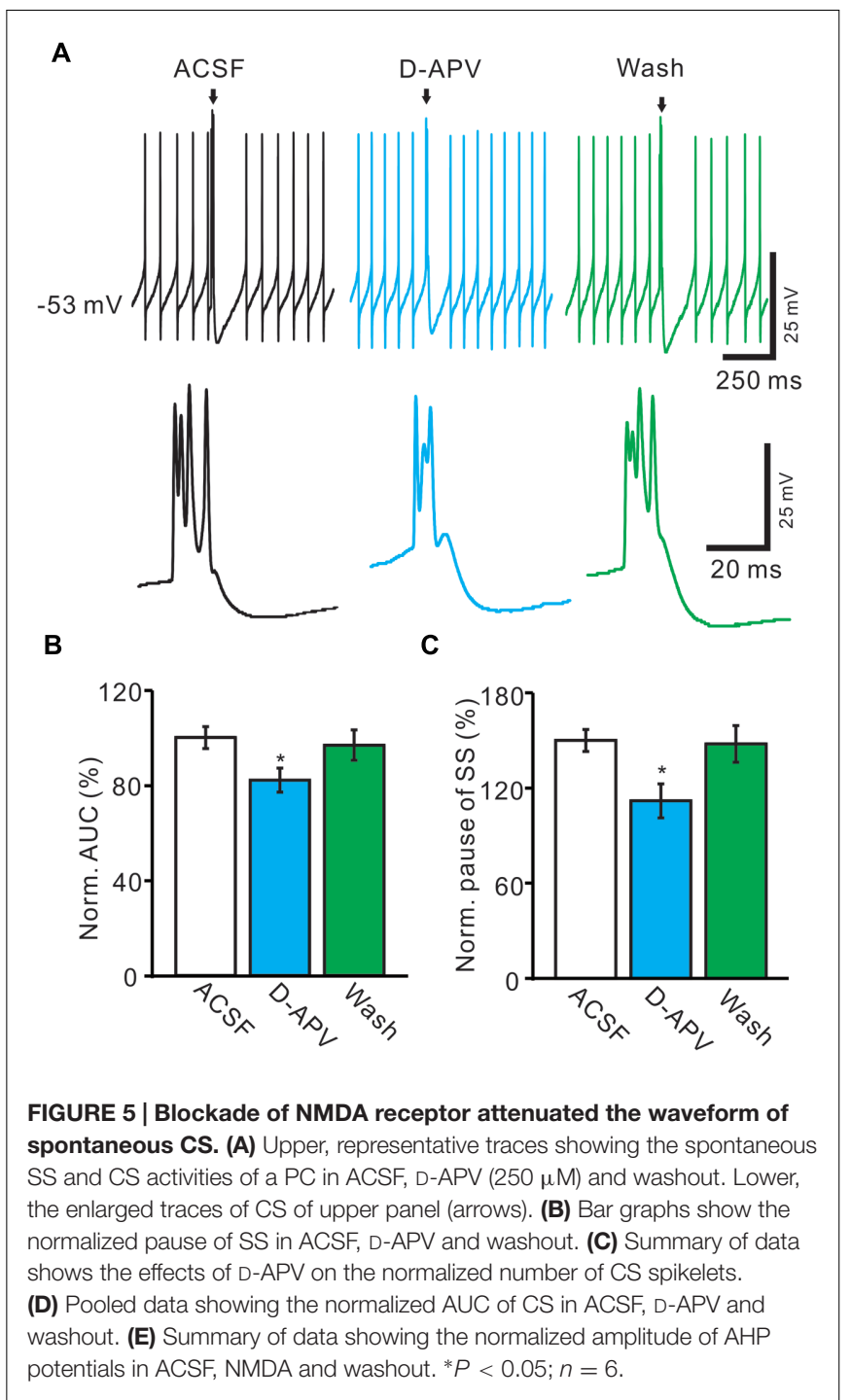

CS activity, suggesting that post-synaptic NMDA receptors of CF-PC synapses play important roles in the regulation of spontaneous CS activity in vivo in mice.

\section{Properties of the Spontaneous CS Discharge In vivo}

Under in vivo conditions, CF discharge can control the frequency and pattern of PC spike output by punctuating tonic activity with a variable duration pauses, slow the frequency of SS discharge (Ebner and Bloedel, 1981; Ebner et al., 1983; Barmack and Yakhnitsa, 2003; Cerminara and Rawson, 2004; Loewenstein et al., 2005). Removal of CF inputs uncovers an increase in SS discharge rate or even a slow oscillatory pattern of background and PC SS discharge that returns to tonic activity when CF activity is reinstated (Colin et al., 1980; Montarolo et al., 1982; Simpson et al., 1996; Cerminara and Rawson, 2004). The ability for $\mathrm{CF}$ inputs to restore tonic discharge in vivo is considered partly due to a block of the mechanisms that give rise to an intrinsic trimodal pattern of PC output (McKay et al., 2007). 


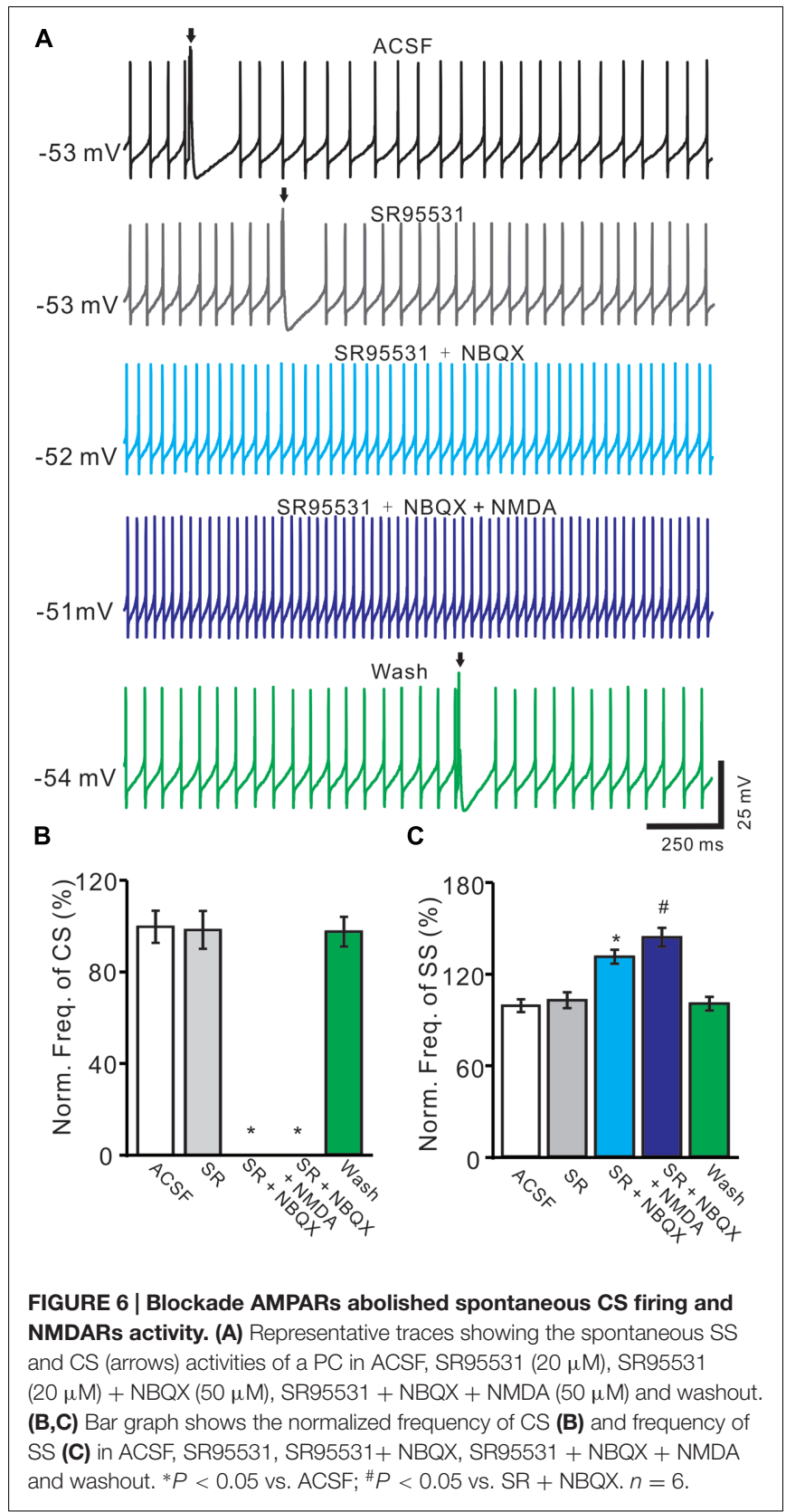

Therefore, CS is thought to represent a critical signal for the operation of the cerebellar cortex, conveying both timing information (Welsh and Llinás, 1996) and triggering synaptic plasticity (Gilbert and Thach, 1977; Hansel et al., 2001; Ito, 2001).

The possible mechanisms underlying CFs activity are usually investigated by simulation of CF to evoke a CS-like depolarization under in vivo and in vitro conditions. However, the stimulationevoked CS-like depolarization could not fully replicate the actions of a CS evoked by synaptic input under in vivo conditions (Reynolds and Hartell, 2000). Electrical stimulation of CF evoked CS followed by a slow after-depolarization (ADP) and an AHP (Schmolesky et al., 2005), whereas the spontaneous CF activity evoked CS followed by AHP in vivo in mice. Under in vitro conditions, strong electrical stimulation of CFs afferents induced ADP which has been considered to be mediated by NMDARs (Piochon et al., 2007) or by metabotropic glutamate receptors (Yuan et al., 2007). However, spontaneous activity of CS in vivo could induce a brief depolarization of PCs, resulting in rapid $\mathrm{Ca}^{2+}-\mathrm{Na}^{+}$bursts and prolonged increases in $\mathrm{Ca}^{2+}$ concentrations (Miyakawa et al., 1992; Maeda et al., 1999). The $\mathrm{Ca}^{2+}$ flowing into PCs triggers a net outward current through $\mathrm{Ca}^{2+}$-dependent $\mathrm{K}^{+}$currents, which exhibited AHP after CS firing. The CS-evoked AHP has been assumed to be a key effecter of the CF-evoked pause and the spike firing activity of SS (Hounsgaard and Midtgaard, 1989).

\section{NMDARs Contribute to Spontaneous CS Discharge in Cerebellar PCs}

$\mathrm{N}$-methyl-D-aspartate receptors are widely expressed in the central nervous system, playing critical roles in synaptic transmission, synaptic plasticity and synaptogenesis (Dingledine et al., 1999; Cull-Candy et al., 2001; Van Zundert et al., 2004). Under in vitro conditions, it has been assumed that NMDARs contribute less to CF stimulation evoked inward currents (Otis et al., 1997; Auger and Attwell, 2000). Recently, however, it was demonstrated that NMDARs contributed to the CF response in vitro in mice (Piochon et al., 2007, 2010). In this study, we showed that extracellular application of NMDA enhanced the waveform of spontaneous CS-evoked inward currents, which expressed increases in the AUC and spikelets of CS, suggesting that NMDA enhanced CF-PC synaptic transmission via activation of NMDARs at CF-PC synapses. Our results are supported by several previous studies (Piochon et al., 2007, 2010; Renzi et al., 2007; Bidoret et al., 2009). First, NMDARs contain NMDAR2A and/or NMDAR2-B subunits are indeed post-synaptically expressed at CF-PC synapses in adult mice, which contributed to the waveform of CS induced by the CF stimulation in cerebellar slices (Piochon et al., 2007). Dendritic patch-clamp recording showed that $\mathrm{CR}$ responses were reduced by NMDARs blocker, D-APV (Piochon et al., 2010). Furthermore, CF stimulation can evoke NMDARs-mediated EPSCs at CF-PC synapses, which is mediated mainly by $\mathrm{NMDAR}_{2 \mathrm{~A}}$-containing receptors in adult $\mathrm{NMDAR}_{2 \mathrm{D}}$ knockout mice (Renzi et al., 2007). Moreover, functional NMDARs in PCs of 2-3-months-old rats have also been demonstrated in CF-evoked EPSCs (Bidoret et al., 2009). In addition, our data showed that application of NMDARs antagonist attenuated the waveform of spontaneous CS, which expressed decreases in the AUC and spkelet number of the spontaneous CS, confirming that CF-PC synaptic NMDARs contributed to the spontaneous CS spike firing in living mice.

In addition, our present results showed that activating and blocking NMDARs modulated the pause of SS firing, suggesting that PF-PC synaptic NMDARs contributed to SS output of PCs via a post-synaptic mechanism. The CS-evoked AHP has been assumed to be a key effecter of the CF-evoked pause and the spike firing activity of SS (Hounsgaard and Midtgaard, 1989). Our present results showed that NMDA significantly increasing the amplitude, half-width and decay time of the spontaneous CS-evoked AHP currents, whereas D-APV attenuated the 
amplitude of CS-evoked AHP currents. These results suggested that CF-PC synaptic NMDARs contributed to SS output of PCs via modulation of AHP activity under in vivo conditions. It has been reported that CF stimulation evoked inward currents which are mediated predominantly by AMPARs (Otis et al., 1997), and the AMPA receptor antagonist, NBQX abolished the CS and the its associated calcium transient in mouse cerebellar slices (Yuan et al., 2007). Consistent with previous studies (Otis et al., 1997; Yuan et al., 2007), our results showed that the spontaneous CS firing was abolished by AMPARs antagonist, indicated that the spontaneous activity of CSs was mediated predominantly by AMPARs under physiological conditions. However, NMDA could not reverse the CS activity in the presence of AMPARs antagonist, suggesting that the spontaneous CSs firing-evoked activity of NMDARs was dependent on the AMPARs activation. It was demonstrates that the CS-induced depolarization is sufficient to relieve the $\mathrm{Mg}^{2+}$ block of NMDA-Rs and to allow them to be activated during the CS firing (Piochon et al., 2007). In addition, stimulation CF evoked NMDA-mediated CF-EPSP in absence of $\mathrm{Mg}^{2+}$ and AMPARs activity, which was completely abolished by $\mathrm{D}-\mathrm{APV}$ and $\mathrm{Mg}^{2+}$ in mouse cerebellar PCs in vitro (Piochon et al., 2007). These results indicate that activation of CF could evoke NMDA receptor-mediated currents in absence of AMPARs activation, but NMDA receptors blocker, $\mathrm{Mg}^{2+}$ should be removed. Collectively, our present results suggest that the spontaneous activity of CF afferents induces glutamate release into CF-PC synapses, which activates post-synaptic AMPARs and resulting in a strong depolarization of post-synaptic membrane (inward currents) in vivo in mice. This strong depolarization removes NMDARs blocker, $\mathrm{Mg}^{2+}$, therefore, $\mathrm{Ca}^{2+}$ influx into PC somas from NMDARs and induces an increase in intracellular $\mathrm{Ca}^{2+}$ level (Miyakawa et al., 1992; Maeda et al., 1999). The increase of $\mathrm{Ca}^{2+}$ concentration could further activate $\mathrm{Ca}^{2+}$ dependent $\mathrm{K}^{+}$currents, resulting in an enhance of AHP activity and a increase in pause of SS firing (Hounsgaard and Midtgaard, 1989).

\section{Physiological Significant of NMDARs Activity in CF-PC Synapses}

The predominantly studied form of cerebellar plasticity is longterm depression (LTD) at PF to PC synapses, which results

\section{REFERENCES}

Auger, C., and Attwell, D. (2000). Fast removal of synaptic glutamate by postsynaptic transporters. Neuron 28, 547-558. doi: 10.1016/S08966273(00)00132-X

Barmack, N. H., and Yakhnitsa, V. (2003). Cerebellar climbing fibers modulate simple spikes in Purkinje cells. J. Neurosci. 23, 7904-7916.

Bidoret, C., Ayon, A., Barbour, B., and Casado, M. (2009). Presynaptic NR2A-containing NMDA receptors implement a high-pass filter synaptic plasticity rule. Proc. Natl. Acad. Sci. U.S.A. 106, 14126-14131. doi: 10.1073/pnas.0904284106

Billard, J. M., and Pumain, R. (1989). Loss of N-methyl-D-aspartate sensitivity of cerebellar Purkinje cells after climbing fiber deafferentation. Neurosci. Lett. 106, 199-204. doi: 10.1016/0304-3940(89)90226-7

Cerminara, N. L., and Rawson, J. A. (2004). Evidence that climbing fibers control an intrinsic spike generator in cerebellar Purkinje cells. J. Neurosci. 24, 4510-4517. doi: 10.1523/JNEUROSCI.4530-03.2004 from $\mathrm{PF}$ and $\mathrm{CF}$ co-activation and is assumed to mediate forms of cerebellar motor learning (Ito et al., 1982; Ito, 2002). CF activity provides widespread $\mathrm{Ca}^{2+}$ transients (Ross and Werman, 1987; Konnerth et al., 1992; Miyakawa et al., 1992), which are required for PF-LTD induction (Sakurai, 1990; Konnerth et al., 1992). In principle, CF-PC synaptic NMDARs could mediate a phasic influx of $\mathrm{Ca}^{2+}$ with a spatiotemporal profile potentially different from that of $\mathrm{Ca}^{2+}$ elevation associated with CF-evoked CSs (Hartmann and Konnerth, 2005). Importantly, probability of LTD and long-term potentiation (LTP) at PF inputs is under control of the CF (Coesmans et al., 2004), which itself undergoes $\mathrm{Ca}^{2+}$-dependent LTD (Hansel and Linden, 2000). NMDA receptors are post-synaptically expressed at CFPC synapses in young adult/adult mice (Piochon et al., 2007), and are required for LTD induction after onset of expression (Piochon et al., 2010). Single pulse stimulation of CF leads to a large all-or-none response in the dendrite (Davie et al., 2008; Ohtsuki et al., 2009), which is strong enough to activate NMDARs signaling, and ultimately evokes a CS in PC somatic recordings in vitro, and these effects are expected to favor $\mathrm{Ca}^{2+}$ entry in the dendrites as well as their propagation (Schmolesky et al., 2002). In addition, NMDA signaling may provide the calcium transients that activate calcium-dependent SK2-type potassium conductance that underlie the pause. Plasticity of these SK2 channels mediates plasticity of the pause itself (Grasselli et al., 2016).

\section{AUTHOR CONTRIBUTIONS}

Conception and design of experiments: C-PC, D-LQ. Performance of experiments: HL,YL. Analysis of data: C-PC, D-LQ. Contribution of reagents/materials/analysis tools: Y-HB. Writing of the manuscript: C-PC, D-LQ.

\section{ACKNOWLEDGMENT}

This work was supported by the National Natural Science Foundations of China (31060138; 81260208; 81160142; 31460261; 20150101070JC).

Chu, C. P., Bing, Y. H., Liu, Q. R., and Qiu, D. L. (2011a). Synaptic responses evoked by tactile stimuli in Purkinje cells in mouse cerebellar cortex crus II. PLoS ONE 6:e22752. doi: 10.1371/journal.pone.0022752

Chu, C. P., Bing, Y. H., and Qiu, D. L. (2011b). Sensory stimulus evokes inhibition rather than excitation in cerebellar Purkinje cells in vivo in mice. Neurosci. Lett. 487, 182-186. doi: 10.1016/j.neulet.2010.10.018

Coesmans, M., Weber, J. T., De Zeeuw, C. I., and Hansel, C. (2004). Bidirectional parallel fiber plasticity in the cerebellum under climbing fiber control. Neuron 44, 691-700. doi: 10.1016/j.neuron.2004.10.031

Colin, F., Manil, J., and Desclin, J. C. (1980). The olivocerebellar system. I. Delayed and slow inhibitory effects: an overlooked salient feature of cerebellar climbing fibers. Brain Res. 187, 3-27. doi: 10.1016/0006-8993(80)90491-6

Cull-Candy, S., Brickley, S., and Farrant, M. (2001). NMDA receptor subunits: diversity, development and disease. Curr. Opin. Neurobiol. 11, 327-335. doi: 10.1016/S0959-4388(00)00215-4

Cull-Candy, S. G., Brickley, S. G., Misra, C., Feldmeyer, D., Momiyama, A., and Farrant, M. (1998). NMDA receptor diversity in the cerebellum: identification 
of subunits contributing to functional receptors. Neuropharmacology 37, 13691380. doi: 10.1016/S0028-3908(98)00119-1

Davie, J. T., Clark, B. A., and Häusser, M. (2008). The origin of the complex spike in cerebellar Purkinje cells. J. Neurosci. 28, 7599-7609. doi: 10.1523/JNEUROSCI.0559-08.2008

Dingledine, R., Borges, K., Bowie, D., and Traynelis, S. F. (1999). The glutamate receptor ion channels. Pharmacol. Rev. 51, 7-62.

Dupont, J. L., Gardette, R., and Crepel, F. (1987). Postnatal development of the chemosensitivity of rat cerebellar Purkinje cells to excitatory amino acids. Dev. Brain Res. 34, 59-68. doi: 10.1016/0165-3806(87)90195-7

Ebner, T. J., and Bloedel, J. R. (1981). Role of climbing fiber afferent input in determining responsiveness of Purkinje cells to mossy fiber inputs. J. Neurophysiol. 45, 962-971.

Ebner, T. J., Yu, Q. X., and Bloedel, J. R. (1983). Increase in Purkinje cell gain associated with naturally activated climbing fiber input. J. Neurophysiol. 50, 205-219.

Eccles, J. C., Llinas, R., and Sasaki, K. (1966). The excitatory synaptic action of climbing fibres on the Purkinje cells of the cerebellum. J. Physiol. 182, 268-296. doi: 10.1113/jphysiol.1966.sp007824

Farrant, M., Feldmeyer, D., Takahashi, T., and Cull-Candy, S. G. (1994). NMDAreceptor channel diversity in the developing cerebellum. Nature 368, 335-339. doi: $10.1038 / 368335 \mathrm{a} 0$

Gilbert, P. F. C., and Thach, W. T. (1977). Purkinje cell activity during motor learning. Brain Res. 128, 309-328. doi: 10.1016/0006-8993(77)90997-0

Grasselli, G., He, Q., Wan, V., Adelman, J. P., Ohtsuki, G., and Hansel, C. (2016). Activity-dependent plasticity of spike pauses in cerebellar Purkinje cells. Cell Rep. 14, 2546-2553. doi: 10.1016/j.celrep.2016.02.054

Hafidi, A., and Hillman, D. E. (1997). Distribution of glutamate receptors GluR $2 / 3$ and NR1 in the developing rat cerebellum. Neuroscience 81, 427-436. doi: $10.1016 /$ S0306-4522(97)00140-1

Hansel, C., and Linden, D. J. (2000). Long-term depression of the cerebellar climbing fiber-Purkinje neuron synapse. Neuron 26, 473-482. doi: 10.1016/S0896-6273(00)81179-4

Hansel, C., Linden, D. J., and D'Angelo, E. (2001). Beyond parallel fiber LTD: the diversity of synaptic and non-synaptic plasticity in the cerebellum. Nat. Neurosci. 4, 467-475.

Hartmann, J., and Konnerth, A. (2005). Determinants of postsynaptic Ca2+ signaling in Purkinje neurons. Cell Calcium 37, 459-466. doi: 10.1016/j.ceca.2005.01.014

Hounsgaard, J., and Midtgaard, J. (1989). Synaptic control of excitability in turtle cerebellar Purkinje cells. J. Physiol. 409, 157-170. doi: 10.1113/jphysiol.1989.sp017490

Ito, M. (1984). The Cerebellum and Neural Control. New York, NY: Raven Press.

Ito, M. (2001). Cerebellar long-term depression: characterization, signal transduction, and functional roles. Physiol. Rev. 81, 1143-1195.

Ito, M. (2002). The molecular organization of cerebellar long-term depression. Nat. Rev. Neurosci. 3, 896-902. doi: 10.1038/nrn962

Ito, M., Sakurai, M., and Tongroach, P. (1982). Climbing fibre induced depression of both mossy fibre responsiveness and glutamate sensitivity of cerebellar Purkinje cells. J. Physiol. 324, 113-134. doi: 10.1113/jphysiol.1982. sp014103

Konnerth, A., Dreessen, J., and Augustine, G. J. (1992). Brief dendritic calcium signals initiate long-lasting synaptic depression in cerebellar Purkinje cells. Proc. Natl. Acad. Sci. U.S.A. 89, 7051-7055. doi: 10.1073/pnas.89. 15.7051

Konnerth, A., Llano, I., and Armstrong, C. M. (1990). Synaptic currents in cerebellar Purkinje cells. Proc. Natl. Acad. Sci. U.S.A. 87, 2662-2665. doi: 10.1073/pnas.87.7.2662

Liu, H., Zhao, S. N., Zhao, G. Y., Sun, L., Chu, C. P., and Qiu, D. L. (2014). $\mathrm{N}$-methyl-d-aspartate inhibits cerebellar Purkinje cell activity via the excitation of molecular layer interneurons under in vivo conditions in mice. Brain Res. 1560, 1-9. doi: 10.1016/j.brainres.2014.03.011

Llano, I., Leresche, N., and Marty, A. (1991). Calcium entry increases the sensitivity of cerebellar Purkinje cells to applied GABA and decreases inhibitory synaptic currents. Neuron 6, 565-574. doi: 10.1016/0896-6273(91)90 059-9

Loewenstein, Y., Mahon, S., Chadderton, P., Kitamura, K., Sompolinsky, H., Yarom, Y., et al. (2005). Bistability of cerebellar Purkinje cells modulated by sensory stimulation. Nat. Neurosci. 8, 202-211. doi: 10.1038/nn 1393

Maeda, H., Ellis-Davies, G. C. R., Ito, K., Miyashita, Y., and Kasai, H. (1999). Supralinear $\mathrm{Ca} 2+$ signaling by cooperative and mobile $\mathrm{Ca} 2+$ buffering in Purkinje neurons. Neuron 24, 989-1002. doi: 10.1016/S0896-6273(00) 81045-4

McKay, B. E., Engbers, J. D. T., Mehaffey, W. H., Gordon, G. R. J., Molineux, M. L., Bains, J. S., et al. (2007). Climbing fiber discharge regulates cerebellar functions by controlling the intrinsic characteristics of Purkinje cell output. J. Neurophysiol. 97, 2590-2604. doi: 10.1152/jn.00627. 2006

Miyakawa, H., Lev-Ram, V., Lasser-Ross, N., and Ross, W. N. (1992). Calcium transients evoked by climbing fiber and parallel fiber synaptic inputs in guinea pig cerebellar Purkinje neurons. J. Neurophysiol. 68, $1178-1189$.

Montarolo, P. G., Palestini, M., and Strata, P. (1982). The inhibitory effect of the olivocerebellar input on the cerebellar Purkinje cells in the rat. J. Physiol. 332, 187-202. doi: 10.1113/jphysiol.1982.sp014409

Nakagawa, S., Watanabe, M., and Inoue, Y. (1996). Altered gene expression of the N-Methyl-d-Aspartate receptor channel subunits in Purkinje cells of the staggerer mutant mouse. Eur. J. Neurosci. 8, 2644-2651. doi: 10.1111/j.14609568.1996.tb01559.x

Neyton, J., and Paoletti, P. (2006). Relating NMDA receptor function to receptor subunit composition: limitations of the pharmacological approach. J. Neurosci. 26, 1331-1333. doi: 10.1523/JNEUROSCI.5242-05.2006

Ohtsuki, G., Piochon, C., and Hansel, C. (2009). Climbing fiber signaling and cerebellar gain control. Front. Cell. Neurosci. 3:4. doi: 10.3389/neuro.03. 004.2009

Otis, T. S., Kavanaugh, M. P., and Jahr, C. E. (1997). Postsynaptic glutamate transport at the climbing fiber-Purkinje cell synapse. Science 277, 1515-1518. doi: 10.1126/science.277.5331.1515

Piochon, C., Irinopoulou, T., Brusciano, D., Bailly, Y., Mariani, J., and Levenes, C. (2007). NMDA receptor contribution to the climbing fiber response in the adult mouse Purkinje cell. J. Neurosci. 27, 10797-10809. doi: 10.1523/JNEUROSCI.2422-07.2007

Piochon, C., Levenes, C., Ohtsuki, G., and Hansel, C. (2010). Purkinje cell NMDA receptors assume a key role in synaptic gain control in the mature cerebellum. J. Neurosci. 30, 15330-15335. doi: 10.1523/JNEUROSCI.4344-10. 2010

Renzi, M., Farrant, M., and Cull-Candy, S. G. (2007). Climbing-fibre activation of NMDA receptors in Purkinje cells of adult mice. J. Physiol. 585, 91-101. doi: 10.1113/jphysiol.2007.141531

Reynolds, T., and Hartell, N. A. (2000). An evaluation of the synapse specificity of long-term depression induced in rat cerebellar slices. J. Physiol. 527, 563-577. doi: $10.1111 / j .1469-7793.2000 .00563 . x$

Rosenmund, C., Legendre, P., and Westbrook, G. L. (1992). Expression of NMDA channels on cerebellar Purkinje cells acutely dissociated from newborn rats. J. Neurophysiol. 68, 1901-1905.

Ross, W. N., and Werman, R. (1987). Mapping calcium transients in the dendrites of Purkinje cells from the guinea-pig cerebellum in vitro. J. Physiol. 389, 319-336. doi: 10.1113/jphysiol.1987.sp016659

Sakurai, M. (1990). Calcium is an intracellular mediator of the climbing fiber in induction of cerebellar long-term depression. Proc. Natl. Acad. Sci. U.S.A. 87, 3383-3385. doi: 10.1073/pnas.87.9.3383

Schmolesky, M. T., De Zeeuw, C. I., and Hansel, C. (2005). Climbing fiber synaptic plasticity and modifications in Purkinje cell excitability. Prog. Brain Res. 148, 81-94. doi: 10.1016/S0079-6123(04)48008-X

Schmolesky, M. T., Weber, J. T., Zeeuw, C. I., and Hansel, C. (2002). The making of a complex spike: ionic composition and plasticity. Ann. N. Y. Acad. Sci. 978, 359-390. doi: 10.1111/j.1749-6632.2002.tb07581.x

Simpson, J. I., Wylie, D. R., and De Zeeuw, C. I. (1996). On climbing fiber signals and their consequence (s). Behav. Brain Sci. 19, 384-398. doi: 10.1017/S0140525X00081991

Thomson, A. M. (2000). Facilitation, augmentation and potentiation at central synapses. Trends Neurosci. 23, 305-312. doi: 10.1016/S0166-2236(00)01 580-0

Van Zundert, B., Yoshii, A., and Constantine-Paton, M. (2004). Receptor compartmentalization and trafficking at glutamate synapses: a developmental 
proposal. Trends Neurosci. 27, 428-437. doi: 10.1016/j.tins.2004. 05.010

Welsh, J. P., and Llinás, R. (1996). Some organizing principles for the control of movement based on olivocerebellar physiology. Prog. Brain Res. 114, 449-461. doi: 10.1016/S0079-6123(08)63380-4

Yuan, Q., Qiu, D. L., Weber, J. T., Hansel, C., and Knöpfel, T. (2007). Climbing fiber-triggered metabotropic slow potentials enhance dendritic calcium transients and simple spike firing in cerebellar Purkinje cells. Mol. Cell. Neurosci. 35, 596-603. doi: 10.1016/j.mcn.2007. 05.004
Conflict of Interest Statement: The authors declare that the research was conducted in the absence of any commercial or financial relationships that could be construed as a potential conflict of interest.

Copyright (c) $2016 \mathrm{Liu}$, Lan, Bing, Chu and Qiu. This is an open-access article distributed under the terms of the Creative Commons Attribution License (CC BY). The use, distribution or reproduction in other forums is permitted, provided the original author(s) or licensor are credited and that the original publication in this journal is cited, in accordance with accepted academic practice. No use, distribution or reproduction is permitted which does not comply with these terms. 